NASA Technical Memorandum 107208

AIAA-96-2261

\title{
An Overview of Aeropropulsion Wind Tunnel Productivity Improvements at the NASA Lewis Research Center
}

Allen Arrington, Edward Becks, Philip Blumenthal and John DeArmon NYMA, Inc.

Brook Park, Ohio

Gary Klann, Timothy Bencic, Timothy McCartney, Joe Panek, Osvaldo Rivera, James Roeder, and David Stark

Lewis Research Center

Cleveland, Ohio

Prepared for the

19th Advanced Measurement and Ground Testing Technology Conference sponsored by the American Institute of Aeronautics and Astronautics

New Orleans, Louisiana, June 17-20, 1996

National Aeronautics and

Space Administration 


\title{
AN OVERVIEW OF AEROPROPULSION WIND TUNNEL PRODUCTIVITY IMPROVEMENTS AT THE NASA LEWIS RESEARCH CENTER
}

\author{
Allen Arrington,* Edward Becks, Philip Blumenthal, and John DeArmon \\ NYMA, Inc. \\ Brook Park, Ohio 44142 \\ and \\ Gary Klann, Timothy Bencic, Timothy McCartney, Joe Panek, \\ Osvaldo Rivera, James Roeder, and David Stark \\ National Aeronautics and Space Administration \\ Lewis Research Center \\ Cleveland, Ohio 44135
}

\section{Summary}

Enhancing wind tunnel test productivity in terms of increased efficiency, reduced cost, and expanded flexibility is a high-priority goal of the NASA Lewis Research Center's Aeropropulsion Facilities and Experiments Division. Over the past several years, several significant productivity improvements were implemented: test times were shortened by using facility and test article automation; additional flexibility was provided to the research customer by using the remote-access control room and by expanding facility operating envelopes; facility throughput was greatly increased and electric power cost for facility operation reduced by using the three-shift operation. One method being used to reduce electric power costs and expand the facility operating envelop in the 8- by 6-Foot Supersonic Wind Tunnel is operating the drive system with only one of the three drive motors. Metrics are being used to document several categories of facility utilization, which in turn allows tracking of test productivity. This paper provides an overview of the productivity improvements already in place in the large wind tunnels at NASA Lewis and presents plans for future improvements.

\section{Introduction}

Issues concerning wind tunnel test productivity are becoming more important in light of current reductions in budgets and government downsizing, affecting the funding and labor needed to operate and maintain facilities. To meet the challenges imposed by these reductions it is necessary to improve the way tests are conducted. Reducing test costs and cycle times will stretch the limited research dollars. New operating methods will also provide the research customer increased flexibility to conduct tests in a large wind tunnel.
The primary goal of the Aeropropulsion Facilities and Experiments Division (AFED) is to improve the general productivity in all the NASA Lewis Research Center aeropropulsion test facilities and to efficiently provide research customers with high-quality test data at low cost. Much of this effort has focused on the four large wind tunnels at Lewis: the 8- by 6-Foot Supersonic Wind Tunnel, the 9- by 15-Foot Low-Speed Wind Tunnel, the 10 - by 10 -Foot Supersonic Wind Tunnel, and the 6- by 9-Foot Icing Research Tunnel (Figs. 1 to 3 ). With respect to wind tunnel productivity, the AFED philosophy is to reduce test cost, improve efficiency, and provide test operation flexibility. Studies of all aspects of wind tunnel testing have revealed that productivity can be enhanced by modifying operating procedures and methods, expanding facility capabilities, automating the facility and test articles, and using remote test site access. Several of these concepts have already been successfully implemented in the propulsion wind tunnel facilities at NASA Lewis and have significantly improved productivity. Table I summarizes the productivity improvements described herein.

\section{Remote Access Control Room}

Testing in the Lewis wind tunnel facilities usually requires hands-on participation by the research engineer to expedite the process. Real-time presentation of acquired data is essential and in the past has only been available in the facility control room. Typically, any external customer had to expend considerable resources on travel to staff the test at a remote site. At best, the staffing was a tradeoff between available travel dollars and the correct skill mix to support the test. To improve productivity and the testing process, Lewis developed the Remote Access Control

*Member AIAA 
Room (RACR), which uses off-the-shelf video conferencing software integrated with existing facility data systems to provide real-time test data to a remote site. Thus, an engineer at the remote site can monitor real-time data and participate in the test as though present in the facility control room.

In the past at Lewis, access to test data from a remote site was provided in different ways, each solution attempting to reduce acquisition time so as to expedite testing. The RACR advanced this concept another level by duplicating all the real-time tools available in the control room for use at the remote site so that the test engineer could participate as the test proceeded. This real-time presentation includes onceper-second updates of alphanumeric and graphics data from the steady-state data system and transient data from the dynamic data system as it is acquired. Integrated into the same platform are video data such as schlieren photography, pressure sensitive paint, and sheet laser. Additionally, video conferencing is available to facilitate communications between the two locations. By providing all these tools on one or more workstations, the engineer at the remote site can participate in the test in the same manner as those in the facility control room. Figure 4 presents a typical RACR display showing steady-state and dynamic data output and video conference communications. Reference 1 gives additional information on the Remote Access Control Room operation.

The most immediate benefit of the RACR is that it cuts cost by reducing or eliminating travel dollars to support a test at a distant facility. As related to productivity, another benefit is increased participation by the customer whose input directs the test on-line and ultimately shortens the overall program. Test efficiency is achieved by allowing an engineer who would not have otherwise traveled to participate in the test and to ensure that the right skills mix be available via the RACR.

\section{Test Article Automation}

Automation of the test article is another method being used to increase test productivity in the Lewis wind tunnel facilities. The philosophy is to use a building block approach with regard to data, facility control settings, and test article control systems. These blocks are separate entities with communication/feedback between them so that each system can be optimized independently. Tradeoffs normally associated with complex integrated systems are eliminated. Also, upgrades can be implemented with significantly fewer resources in a more timely manner.

Two systems in use at Lewis are the Test Matrix Sequencer(TMS) and the Programmable Actuator Control
System (PACS). A typical operational sequence for either system involves automatically setting model/probe positions, waiting for transients to decay, signaling the data system to record, and then waiting for it to acknowledge recording before proceeding with the next condition. Configuration files are set up before the test run but the test operator can easily intervene during testing to modify conditions. Ramping times, settling delays, and various discrete events can be incorporated in the program. Setting model/probe positions automatically rather than manually yields higher data repeatability.

The TMS can be configured with up to 14 analog and 15 digital I/O. It has been used to set test article and probe positions by outputting analog set points to position controllers and using its digital I/O to respond to discrete events. Configuration data are entered in engineering units and run from a spreadsheetlike table which has the capability of storing 50 unique condition settings. Furthermore, these 50 conditions can be incorporated in either the main sequence or up to 3 subsequences. These subsequences can be called many times to create complex test matrices.

The PACS can control up to eight types of motion controllers. Sixty-four actuators can be configured. Data for the positions are entered in engineering units in an ASCII configuration file. These files can be saved and brought up anytime during testing. Editing functions are also available to quickly update the tables as required. On-line diagnostics provide the operator with health monitoring of the motion systems.

The TMS and PACS are standard, modular, and expandable and can be quickly configured. Large blocks of time are not required to set them up before testing. Therefore, using an automated system during the test does not require significantly more time for setup and configuration prior to the test as compared with the setup of a manual system. The amount of test time saved is a function of the complexity of the test article. A model with large numbers of actuated devices is a good candidate for automation although savings and better data repeatability are also possible with only one actuated device. Figure 5 shows how automation saves time. In general, each actuator can be moved manually in $5 \mathrm{sec}$ with $10 \mathrm{sec}$ allowed for data settling after the final move. The automated system requires 15 sec total time to move all devices simultaneously and allow settling time. With a large number of motion systems connected to the PACS, a few additional seconds are required for communications. 


\section{Tunnel Control Systems}

In 1988 , the 8 - by 6 - and 9 - by 15 -Foot Wind Tunnels replaced their 1960's vintage control system (Fig. 6) with the new distributed control system (DCS) shown in Fig. 7. All major systems for controlling the facility were also retrofitted. By integrating all the subsystems controls in one unit, a significant increase in facility performance was realized. The flexible-wall nozzle upstream of the 8 - by 6-ft test section was one of the original systems converted to total automatic control. The automation of this system, while saving 25 percent in total wall travel time, also significantly reduced the stress put on the nearly 50 -yearold equipment by optimizing the control system for the hydraulic screw jacks that bend the wall.

In 1992, the second major system change that contributed to the increased productivity of this facility was replacing the drive motor speed control system This system controls the speed of three 29000 -hp electric motors that are tied to a common shaft and drive the seven-stage axial-flow compressor. The compressor speed was varied between 500 and $875 \mathrm{rpm}$ to produce the desired test section velocity. After an extensive retrofit, the drive motor system was put under the DCS (ref. 2). The system can now control the motor steady-state speed to within $0.4 \mathrm{rpm}$ over a range of 345 to $875 \mathrm{rpm}$ and can balance power between motors to within $0.05 \mathrm{MW}$. In 1995 , the capability of running on one of the three motors was added to extend the low-speed operation of the facility while also providing significant power savings for some existing Mach number conditions.

The automation of this facility using the DCS significantly increased productivity. For instance, before the installation of the DCS, getting the 8 - by 6 - $\mathrm{ft}$ test section from wind off to a Mach-2.0 test condition took between 26 and $30 \mathrm{~min}$. After the retrofit, the same procedure required only 17 to $20 \mathrm{~min}$ because of the optimization and integration of the previously mentioned systems and other wind tunnel systems ( 3 percent savings in tunnel run time). Similar improvements were realized using DCS control in the Icing Research Tunnel and the 10 - by 10 -Foot Supersonic Wind Tunnel.

\section{One-Motor Operation of the 9- by 15-Foot Low-Speed Wind Tunnel}

The 9- by 15-Foot Low-Speed Wind Tunnel test section is located in the return leg of the 8- by 6-Foot Supersonic Wind Tunnel loop; air is moved through both test sections by a seven-stage axial compressor driven by three 29 000-hp electric motors (Fig. 2). The Mach number range of the low-speed test section is 0 to 0.20 . For three- drive motor operation, the Mach number conditions are set by bleeding air from the tunnel loop via the large flow control doors (doors 1 and 2 in Fig. 1), with the compressor operating at $510 \mathrm{rpm}$ (min attainable rotational speed for three-drive motor operation). At the very low Mach number setting of the 9- by $15-\mathrm{ft}$ test section, flow control doors 1 and 2 are almost completely open to bleed off the majority of the airflow through the tunnel, indicating that much of the mass flow and therefore power are being wasted. Power drawn during this mode of operation varies between 15 and $18 \mathrm{MW} / \mathrm{hr}$.

It was suggested in early 1995 that it might be possible to operate the facility drive system using only one electric drive motor. This would produce lower compressor speeds and therefore lower mass flow rates through the tunnel, allowing the Mach number conditions in the low-speed test section to be set without bleeding air through the flow control doors. Normal startup procedure for the drive system is to start each motor singularly with about a 40 -sec interval between starts. This procedure illustrated that it was safe to operate the drive on only one motor. Recent upgrades and modifications to the drive system and installation of a new speed control system facilitated operation on fewer than three motors.

Initial tests of one-motor operation, conducted in spring 1995, proved that the minimum steady-state compressor speed was $337 \mathrm{rpm}$ and that the system drew only $6 \mathrm{MW} / \mathrm{hr}$ at this condition. It was shown that one-motor operation could be used to set Mach number conditions up to 0.14 in the 9 - by 15 -ft test section; three-motor operation was required to set the higher Mach number conditions (there was no savings associated with running only two motors as compared with running three). By operating the 9- by 15 -Foot Supersonic Wind Tunnel using only one drive motor, a savings of up to $10 \mathrm{MW} / \mathrm{hr}$, or $\$ 550 / \mathrm{hr}$, was possible over most of the facility's operating range. A total savings of $\$ 71000$ in electrical power was realized during the first 6 weeks of operation using only one drive motor (10/30 through 12/15/1995). Reference 3 gives additional information on the one-motor operation of the 9- by 15-Foot Low-Speed Wind Tunnel.

\section{Expanding Facility Operating Envelopes}

The operating capabilities of several wind tunnel facilities were expanded or enhanced to provide the customer the greatest possible flexibility to accomplish all test goals. For example, expansion of the Mach number range available will allow a tunnel user to complete more of an overall program test matrix in one facility, thereby reducing the number of facilities needed to cover the entire operating range of a test article or test program. Enhancing 
existing capabilities means that more efficient or less expensive means of setting an operating condition have been developed. Examples of these types of productivity improvements follow.

\section{Low-Speed Operation of the 8- by 6-Foot Supersonic Wind Tunnel}

Another direct result of the one-motor operation of the 9- by 15-Foot Supersonic Wind Tunnel was the simultaneous expansion of the subsonic operating range of the 8- by 6-Foot Supersonic Wind Tunnel. The initial tests of the one-motor operation and subsequent calibration testing showed that the lowest Mach number setting in the 8 - by 6 - $\mathrm{ft}$ test section was reduced from 0.36 to 0.25 . Operating in this mode reduced the Mach number gap between the 9 - by 15 - and 8 - by 6 -ft test sections (as previously mentioned, the Mach number range in the 9- by $15-\mathrm{ft}$ test section is 0 to 0.2 ). Although the Mach number ranges of the two facilities do not quite overlap, the expanded Mach number range in the 8- by 6-ft test section provides a research customer with a nearly continuous Mach range of 0 to 2.0 within the same wind tunnel complex.

The 8- by 6-Foot Supersonic Wind Tunnel can be operated on one drive motor over the Mach number range of 0.25 to 0.5 , which provides some savings in electric power as compared with standard three-motor operation. At Mach 0.5, 22 MW are required for three-motor operation as compared with $17 \mathrm{MW}$ for one motor; at Mach 0.45, $19 \mathrm{MW}$ are needed to run three motors and $13 \mathrm{MW}$ for one motor. Depending on the test conditions needed for a particular test program, operating on one motor could amount to a significant savings in electric power funds.

Setting very low-speed conditions in the 8- by 6 - $\mathrm{ft}$ test section using the air dryer building wingblowers to provide additional overlap of the Mach number ranges of the 8- by 6- and 9- by 15 -ft test sections was also investigated. The wingblowers are used to draw air through the facility air dryer building during the desiccant reactivation cooling cycle. In the past, the wingblowers have been used to draw air through the 9 - by $15-\mathrm{ft}$ test section to set very lowspeed conditions. By properly configuring flow control doors in the tunnel loop and within the air dryer, it was possible to use the wingblowers to set Mach number conditions between 0.01 and 0.09 in the 8 - by 6 -ft test section. The resulting operating ranges of each test section are shown in Fig. 8.

An advantage of this very low-speed capability is the added flexibility it provides a researcher. Most test programs require a fairly wide Mach number range to cover all test operating ranges (takeoff, landing, cruise, dash, etc.) and in many cases, different facilities and test articles are used to study each of these operating conditions. By providing the expanded facility Mach number range, it may be possible to reduce the number of test entries required for a specific test program. There have been several instances where a particular test article was tested in both the 8 - by 6 - and 9 - by 15 -ft test sections so that data were available from Mach 0 to 2.0. By expanding the subsonic operating range of the 8- by 6-ft test section, it is now possible to provide this same Mach number range coverage in one test section. This greatly reduces the tunnel occupancy time required because the test article does not have to be moved from one test section to another.

\section{Off-Design Operation of the 10- by 10-Foot Supersonic} Wind Tunnel

Off-design flexwall nozzle settings. The testing capabilities of the 10-by 10-Foot Supersonic Wind Tunnel were improved recently by a modification of the position control of the flexible-wall nozzle. The wind tunnel, originally designed to set air speeds in 0.1 -Mach increments between Mach 2.0 and 3.5, is now capable of testing at Mach 2.35 in support of NASA's High Speed Research (HSR) program.

The position of each nozzle sidewall, or flexwall, is controlled by a set of cams connected essentially on a common camshaft and previously monitored by a rotary potentiometer on the camshaft. Precision-machined dwells (small constant-radius sections) in the cam profile are used to set the wall position in 0.1-Mach increments. In the past, test data in the 10- by 10-Foot Supersonic Wind Tunnel had always been obtained with the flexwall set at one of its design positions, Mach 2.0 to 3.5 in 0.1 - intervals. The dwell allowed precise positioning of the flexwall nozzle contour even if the positioning of the camshaft was slightly off, which could occur with potentiometer drift. In between the cam dwells are areas of changing radius, or ramps. Testing with the flexwall set on the cam ramps (between the 0.1-Mach increments) could not be done reliably because the flexwall position was not repeatable. Position errors of as much as 0.02 Mach could occur.

An improvement was made to the camshaft position control system to allow testing at the Mach- 2.35 condition, the expected air speed under the wing of the HSR aircraft. The rotary potentiometer was replaced by an optical encoder which gave a more accurate and repeatable indication of camshaft position. The encoder output was then calibrated to the flexwall position in 0.02-Mach increments between Mach 2.2 and 2.4 (2.22, 2.24, etc.) and at Mach 2.35. Followup measurements showed that the accuracy of setting the flexwall position between the 
cam dwells was increased by an order of magnitude to within \pm 0.002 Mach. This improved accuracy was acceptable for the planned HSR testing in the 10- by 10-Foot Supersonic Wind Tunnel.

By calibrating the facility at the off-design flexwall settings, it was possible to provide the Mach-2.35 setting for the HSR test. In addition, it was also shown that the facility could be operated at other off-design flexwall positions. Currently, the facility is calibrated for offdesign points between Mach 2.2 and 2.4 in 0.02-increments, but this range can be extended to meet test needs. The offdesign Mach number settings greatly enhance the flexibility afforded to a research customer.

Mach number suppression by use of gust plate. To support inlet testing at the 10 - by 10 -Foot Supersonic Wind Tunnel, a hydraulically actuated gust plate is available for lowering the local Mach number and disturbing the flow field upstream of the inlet. The local Mach number can be reduced to 1.6. The reduction in Mach number extends the current tunnel Mach envelope, and the disturbances created in the local flow field can be used to develop and verify control logic during inlet testing.

The gust plate is trapezoidal with a leading edge width of 108 in., a trailing edge width of 21.5 in., and an axial length of 72 in. Figure 9 shows a typical gust plate installation in the test section. The gust plate is secured to the ceiling of the tunnel and can be installed, removed, or relocated during any phase of testing. Vertical height and axial station adjustments are performed manually whereas the angle of attack and dynamic oscillations are remotely controlled during testing. Installation of the gust plate normally takes 1 day to complete whereas adjustments to it can be completed in a shift or less. The gust plate is instrumented with 49 steady-state static pressure taps, 2 dynamic transducer taps, and 3 rake mounting pads. The 3 rake pads are located at a centerline and 2 off-centerline positions; a 21-element total pressure rake can be mounted on each pad. The gust plate can be run at all current 10 - by 10-Foot Supersonic Wind Tunnel conditions and can be oscillated to a frequency of $15 \mathrm{~Hz}$ at an amplitude of $\pm 0.5^{\circ}$. Angle-of-attack step changes can also be inputted.

Using the gust plate can eliminate the need for a test entry in a lower Mach number range tunnel to complete a program test matrix. There have been instances when some data were required at Mach 1.6 to augment the data collected in the 10- by 10-Foot Supersonic Wind Tunnel at Mach 2.0 and above. Rather than move the test article from the 10- by 10 -ft test section to another facility (such as the 8 - by 6-Foot Supersonic Wind Tunnel), it proved to be more effective in terms of the time required and the cost to install the gust plate and collect the lower Mach number data in the 10 - by 10 -Foot Supersonic Wind Tunnel. As mentioned, the gust plate can be installed in the test section in 1 day as compared with several weeks to move a test article from one tunnel to another (this time will depend on the complexity of the test article and the availability of another suitable test facility).

Low-speed operation. As a result of the recent successful low-speed (subsonic) operation in the 8- by 6-Foot Supersonic Wind Tunnel using only one drive motor, a similar operational scheme is being investigated in the 10- by 10-Foot Supersonic Wind Tunnel. Proof-of-concept tests conducted in February 1996 showed that the facility could safely be operated using only one of the four electric motors of the primary drive. This operating condition produced a test section Mach number of approximately 0.1 . Additional tests are planned to determine the overall low-speed operating range of the facility.

Low-speed operation of the 10- by 10 -Foot Supersonic Wind Tunnel would again provide the researcher with additional flexibility in planning a test program. Combining low-speed operation and using the gust plate and the design and off-design flexwall Mach number settings would make it possible for a researcher to test from about 0 to Mach 3.5 , thereby covering nearly all possible atmospheric flight regimes (takeoff/landing, climbout, cruise, dash, etc.) in one test facility. This scheme could greatly reduce the total testing portion of a program by eliminating multiple test entries. Also, more testing could be accomplished by using one test article instead of a test article for each wind tunnel.

\section{Dewpoint Calibration of the 10 - by 10 -Foot Supersonic Wind Tunnel}

A new high-response on-line measurement system has been developed to continuously display and record the air stream dewpoint in the NASA Lewis 10 - by 10 -Foot Supersonic Wind Tunnel (ref. 4). Previous electronic instruments suffered from problems such as very slow response, erratic readings, and high susceptibility to contamination. The new system operates over the entire pressure level range of the 10 - by 10 -Foot Supersonic Wind Tunnel (from less than 2 to 45 psia) without the need of a vacuum pump to provide sample flow. The system speeds up tunnel testing, reduces tunnel power costs, and provides the dewpoint input for the data-reduction subroutines that calculate test section conditions.

The new system incorporates a hygrometer with a proprietary moisture sensor built on a low-mass silicon chip that can respond to a step dewpoint change from +18 to $-60{ }^{\circ} \mathrm{C}$ in less than $1 \mathrm{~min}$. The sensor operates 
satisfactorily over a wide variation of flow rates with a line pressure range from vacuum to 4000 psig and contains a closed-loop heater control to eliminate ambient temperature error. The air sample system utilizes the pressure difference across the test section to produce flow through the instrument at all tunnel pressure levels. A dewpoint generator is used to provide a periodic in situ calibration of the system with traceability to national standards. Until the new system was developed, the only reliable measurement used a manually operated instrument that required a slow trial-and-error process to obtain a reading. If the dewpoint reading finally obtained was not suitable for taking data, the tunnel conditions were changed and another manual measurement operation performed. Because of the tunnel drive power consumed during the several minutes required to obtain each reading, this procedure was very costly.

An illustration of the cost savings in terms of electric power follows. Conservatively, a dewpoint measurement using the old system required at least $3 \mathrm{~min}$; during a normal test run, five tunnel conditions were set per run resulting in about $15 \mathrm{~min} /$ run being dedicated to dewpoint measurement. At an average power cost of $\$ 2400 / \mathrm{hr}$ (100 MWh at $\$ 24 / \mathrm{MWh}$ ), about $\$ 600$ of the electric power cost per run was lost during the dewpoint measurements. With the new dewpoint system, no run time is dedicated to the dewpoint measurement. Using the new dewpoint system will result in an electrical power savings of approximately $\$ 50000$ for a 4-month test program operating 5 nights/week.

The new dewpoint measurement system was used during the latest test section calibration test conducted in February 1995. This system allowed for the measurement of variation in the test section Mach number and total pressure recovery as a function of airstream dewpoint (a typical data set is shown in Fig.10). This measurement system resulted in the development of a more accurate tunnel condition subroutine to compute the test section conditions using a mathematical model derived from the calibration data. This subroutine uses the direct inputs from the 10 - by $10-\mathrm{ft}$ dewpoint hygrometer system to provide real-time calculation and display of the corrected test conditions.

In addition to providing more accurate data in less time, the calibration test showed that the operating range of the facility in terms of maximum allowable dewpoint could be increased from -15 to about $0{ }^{\circ} \mathrm{F}$ without degrading the data quality. Previous to the installation of the improved dewpoint measuring system, no data were collected until the dewpoint had fallen to -15 to $-20^{\circ} \mathrm{F}$. Depending on the atmospheric conditions, this process could waste 15 to $45 \mathrm{~min}$ of tunnel operation time. Now that there is a better understanding of the dewpoint effects so that quality data can be obtained at higher dewpoints, much less tunnel running drying time is needed before data collection can begin. Thus, approximately $30 \mathrm{~min}$ of operating time per run (about $\$ 1250 /$ run) can be saved.

\section{On-Line Data System Calibration}

Recently, the data system used for pressure measurement in the 10- by $10-\mathrm{ft}$ Supersonic Wind Tunnel was upgraded to provide improved data accuracy (three times more accurate than the previous system). The old system required a calibration every $20 \mathrm{~min}$ to maintain system accuracy. This calibration was necessitated by reference pressure, power supply, and A/D drift as well as module temperature changes. The new system (1) requires a calibration once every $4 \mathrm{hr}$, (2) incorporates a better power supply and $\mathrm{A} / \mathrm{D}$ and continuously corrects the data for reference pressure fluctuations, and (3) is enclosed in an environmental chamber that maintains a temperature of $75 \pm 2{ }^{\circ} \mathrm{F}$. A check pressure on each module automatically alarms with a drift in the data system.

System calibration requires about $2 \mathrm{~min}$. For an 8 -hr run, the old system required $48 \mathrm{~min}$ of calibration time as compared with $4 \mathrm{~min}$ for the new system. At an average power cost of $\$ 40 / \mathrm{min}$, the old system had about $\$ 1920$ in lost power per run versus $\$ 160$ for the new system.

In terms of productivity, only $3 \mathrm{hr}$ and $36 \mathrm{~min}$ of every $4 \mathrm{hr}$ was usable for data acquisition with the old system (90-percent efficiency). With the new system, $3 \mathrm{hr}$ and $56 \mathrm{~min}$ are available (over 98-percent efficiency), a 9 -percent increase. Over the course of a test program, this increased efficiency will result in a savings of several thousand dollars in electric power costs.

\section{Facility Operational Changes}

\section{Facilities Utilization Process Action Team (FUPAT)}

TheFacilities Utilization Process Action Team (FUPAT) was chartered by the NASA Lewis Research Center's Quality Council to investigate and optimize the current use of scheduled research run time and the throughput of test articles. In addition, the FUPAT was asked to study the feasibility and cost benefits of alternative methods of operating the Lewis facilities.

The Lewis aeropropulsion research facilities, in most cases, require a large amount of centrally supplied services (e.g., combustion air, altitude exhaust, electric power) to operate. As its first step, the FUPAT implemented improvements to the process used to schedule central services and facility operations. In the first year of implementation, the ratio of test hours used versus test 
hours scheduled increased by 10 percent. The amount of "Courtesy Hours" increased by 40 percent. Courtesy hours are periods when the central equipment is operating for scheduled users and excess capacity is available to other users. In 1995, the FUPAT received an award from NASA Administrator Dan Goldin in recognition of the team's outstanding contribution to NASA Quality Management and the Continual Improvement philosophy.

\section{Expanded Off-Peak Operations}

The NASA Lewis Research Center is the second largest customer of electric power in Ohio, the first being LTV Steel Corporation of Cleveland. Over the past 5 years, the annual laboratory-wide electric power usage has been greater than $220000 \mathrm{MWh}$, costing over \$12 million dollars. In 1994, in response to recommendations from the FUPAT, Lewis instituted "Project Oriented Third Shift Operation for the NASA Lewis 10- by 10-Foot Supersonic Wind Tunnel." This tunnel was selected to be the first facility to operate during third shift because it is the single largest user of electric power and operates relatively independently of the central services. This one facility's productivity significantly improved and the entire laboratory benefitted from reduced electrical power costs.

The NASALewis Research Center purchases its electric power from the local utility, the Cleveland Electric Illuminating Company. The terms of this contract ensure that sufficient power always be available for NASA to perform its mission. In addition, the contract stipulates that NASA receive a reduced rate if it operates during offpeak periods, 10:00 p.m. to 8:00 a.m. The Lewis Research Center staff has aggressively worked to resolve all issues concerning program commitments, work-force constraints, and centralized services that make it so difficult to use this lower cost power. We have also learned that there are major impacts on personnel; productivity improvements and cost reductions have come at a high price.

\section{Using Metrics To Improve Productivity}

The goals of the NASA Lewis Research Center include providing its research customers with high-quality test data at low cost and in as efficient a manner as possible. To this end, the Aeropropulsion Facilities and Experiments Division tracks a variety of facility utilization metrics. One of the most important from a productivity standpoint is total annual run hours for each active aeropropulsion research facility. The bar graphs in Fig. 11 illustrate the increase in total annual run hours at the 10 - by 10 -Foot Supersonic Wind Tunnel achieved in the past since "Project Oriented Third Shift Operation" was instituted. Those in Fig. 12 show the past and projected laboratory-wide electrical power cost savings. Since 1994, Lewis has saved over \$1 million each year for electric power but has increased the amount of research data provided to its customers.

In 1996, the Lewis Research Center expanded its offpeak operation to include the Propulsion System Laboratory (PSL) and the 8- by 6-Foot Supersonic Wind Tunnel and the 9- by 15-Foot Low-Speed Wind Tunnel. As a result, we expect to provide our customers with more research test time with the same or fewer resources. The Propulsion Systems Laboratory (PSL) will begin operating on third shift during the second quarter of 1996 , thereby reducing power costs per run costs by 40 to 50 percent for this single facility. By operating both of these facilities during third shift, the projected cost per MWh will drop to $\$ 47$ in FY1996, a 4-percent decrease.

An example of the benefits of expanded operation is illustrated by the special needs of the 8- by 6-Foot Supersonic Wind Tunnel/9- by 15 -Foot Low-Speed Wind Tunnel complex. This facility has two test sections with a common drive system. Only one test section can be operated at a time, often resulting in scheduling conflicts and testing compromises that tend to lengthen the overall program schedule and completion date. Furthermore, dry air is required to run the 8 - by 6-Foot Supersonic Wind Tunnel at supersonic speeds. Reactivation of the desiccant contained in the air dryer requires $8 \mathrm{hr}$ and is normally done during the first or second shifts. To meet the recent test program requirements, a third shift was added to support the 8 - by 6 -ft/9- by $15-\mathrm{ft}$ complex. Because of power savings considerations, the 8 - by 6 -Foot Supersonic Wind Tunnel was chosen for testing on this shift. Both the 8- by 6-Foot Supersonic Wind Tunnel and the 9- by 15-Foot Low-Speed Wind Tunnel model buildup and preparation and the air dryer reactivations were done on the first and second shifts. The results were that a test expected to require 14 weeks of tunnel occupancy for testing, based on two-shift operation, was shortened to 10 weeks by using three-shift operation, a 40 -percent decrease in tunnel occupancy.

AFED is developing a computerized network system to log and report facility metrics data. The system simplifies the entering of data and provides for consistent sorting of various types of data which include facility, project, individual run, resource costs, facility usage and customer satisfaction surveys. The facility usage section is based on a facility timesheet that covers $24 \mathrm{hr}$ a day, 365 days a year to break down facility time into various detail items under categories such as model installation, facility problems, maintenance, standby time, test time, regular employee leave. 
The metrics system is based on a computerized data base system using customized forms and reports to create a user-friendly program that reduces the amount of data entry required. Most redundant information is available from dropdown list boxes to reduce the number of double entries and the associated problems of inconsistent data. The system will save time by reducing the amount of work required to enter data and by automating the generation of monthly and annual reports that previously were done manually.

\section{Concluding Remarks}

This paper has provided a summary of several of the wind tunnel test productivity improvements that have been and are being implemented at the NASA Lewis Research Center. By developing methods and procedures to reduce facility operating costs and test times, it is possible to directly reduce the cost of a test program Additional flexibility is also being provided to the research customer through remote access to the test and test data, greatly reducing travel costs and allowing the customer to have the correct skills mix of personnel available for all test phases. Increased facility operating ranges have shown a gain in overall productivity. The use of metrics to track general facility operations has indicated the areas where improvements have been made and where further gains can be realized.

\section{References}

1. McCartney, T.P.: Off-Site Test Participation Using the Remote Access Control Room. AIAA Paper 96-0586, 1996.

2. Becks,E.A.;Bencic, T.J.;Blumenthal,P.Z.: Improved Speed Control System for an 87,000 HP Wind Tunnel Drive. NASA TM-106840, 1995.

3. Becks, E.A.: Enhancing the Capabilities of NASA Lewis' $8 \times 6 / 9 \times 15$ Wind Tunnel Complex Through Drive System Modifications. NASA CR-198455, 1996.

4. Blumenthal, P.Z.: High Response Dew Point Measurement System for a Supersonic Wind Tunnel. NASA CR-198453, 1996. 
TABLE I.-PRODUCTIVITY IMPROVEMENTS IN NASA LEWIS RESEARCH CENTER AEROPROPULSION WIND TUNNEL FACILITIES

\begin{tabular}{|c|c|c|c|c|c|}
\hline \multirow[t]{2}{*}{ Improvement item } & \multicolumn{4}{|c|}{ Improvement category } & \multirow[t]{2}{*}{ Payoff } \\
\hline & Cost & $\begin{array}{l}\text { Test } \\
\text { time }\end{array}$ & $\begin{array}{l}\text { Flexi- } \\
\text { bility }\end{array}$ & $\begin{array}{c}\text { Data } \\
\text { quality }\end{array}$ & \\
\hline Remote Access Control Room & $\mathrm{X}$ & & $\mathrm{x}$ & & $\begin{array}{l}\text { Greatly reduces customer's travel costs } \\
\text { Allows customer proper skills mix during testing }\end{array}$ \\
\hline Test article automation & $\mathrm{X}$ & $\mathrm{X}$ & & $\mathrm{X}$ & Provides 20- to 40-percent time savings to set test conditions \\
\hline Tunnel controls & $\mathrm{X}$ & $\mathrm{X}$ & & $\mathrm{X}$ & $\begin{array}{l}\text { Reduces time to make initial tunnel settings by } 30 \text { percent } \\
\text { Reduces time between tunnel settings }\end{array}$ \\
\hline $\begin{array}{l}\text { 9- by } 15 \text {-Foot Low-Speed Wind Tunnel } \\
\text { One-motor operation }\end{array}$ & $\mathrm{X}$ & & & & Saves $10 \mathrm{MW} / \mathrm{hr}(\$ 550 / \mathrm{hr})$ \\
\hline $\begin{array}{l}\text { 8- by 6-Foot Supersonic Wind Tunnel } \\
\text { Low-speed operation (one motor) }\end{array}$ & $\mathrm{X}$ & & $\mathrm{X}$ & & $\begin{array}{l}\text { Saves power at low-speed conditions normally set with three motors } \\
\text { Allows researcher greater latitude in test matrix as result of expanded low-speed operating range }\end{array}$ \\
\hline $\begin{array}{l}\text { 10- by } 10-\text { Foot Supersonic Wind Tunnel } \\
\text { Off-design Mach number settings } \\
\text { Gust plate } \\
\text { One-motor operation (low speed) } \\
\text { Dewpoint measurement system } \\
\text { Dewpoint/calibration update }\end{array}$ & $\mathrm{X}$ & $X$ & $\begin{array}{l}X \\
X \\
X \\
X\end{array}$ & $\begin{array}{l}\mathrm{X} \\
\mathrm{X}\end{array}$ & $\begin{array}{l}\text { Allows greater use of facility; used in support of HST program at M- } 2.35 \text { design point } \\
\text { Allows expanded facility operating range } \\
\text { Allows expanded facility operating range } \\
\text { Reduces time required to measure dewpoint; } \$ 50000 \text { savings in power costs for typical test program } \\
\text { Allows testing at higher dewpoints (expands operating range) as result of better understanding of dewpoint effects }\end{array}$ \\
\hline On-line data system calibration & $\mathrm{X}$ & $\mathrm{X}$ & & & Provides 60-percent reduction in data system calibration time and power cost \\
\hline $\begin{array}{l}\text { Operational changes } \\
\text { Facility Utilization Team } \\
\text { Off-peak/three-shift operation }\end{array}$ & $\mathrm{X}$ & $\begin{array}{l}X \\
X\end{array}$ & & & $\begin{array}{l}\text { Provides 10-percent increase in test hours completed to hours scheduled; } 40 \text {-percent increase in courtesy time; } \\
50 \text {-percent power cost savings during third-shift operation } \\
\text { Allows increase in runs per week (from } 2 \text { to } 3 \text { to } 4 \text { to } 5 \text { ) }\end{array}$ \\
\hline
\end{tabular}




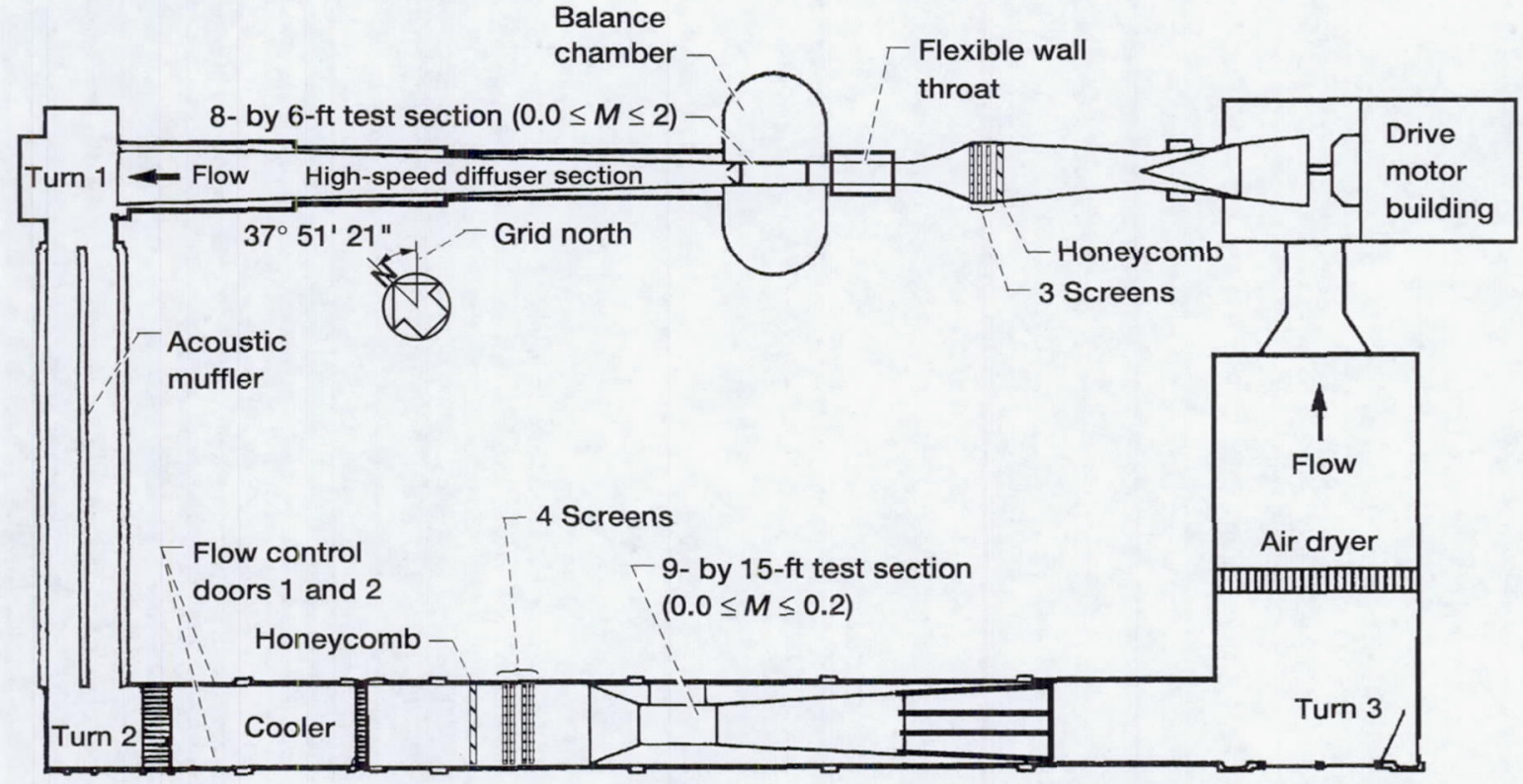

Figure 1.-Layout of 8- by 6-Foot Supersonic/9- by 15-Foot Low-Speed Wind Tunnel complex.

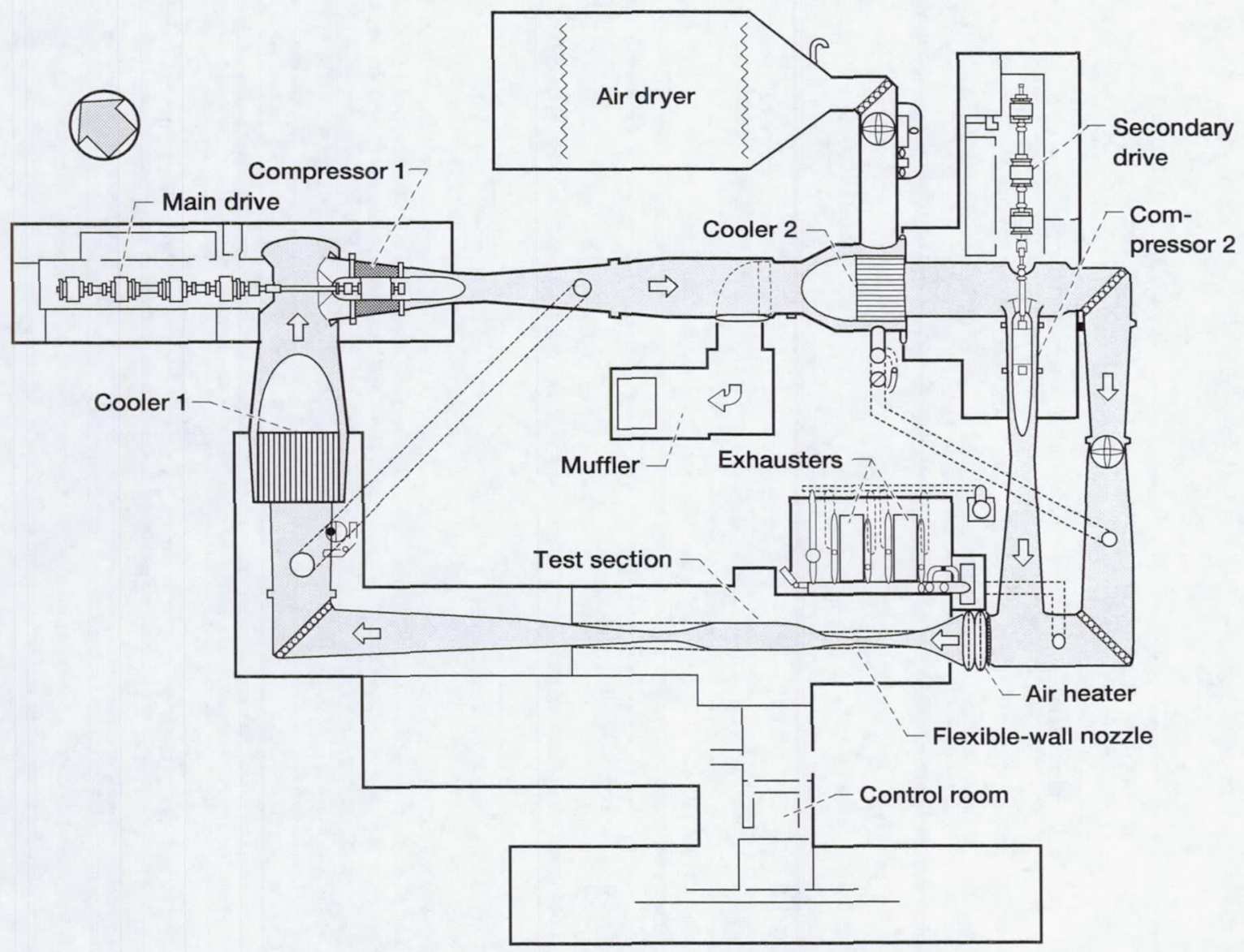

Figure 2.-Layout of 10 - by 10 -Foot Supersonic Wind Tunnel. 


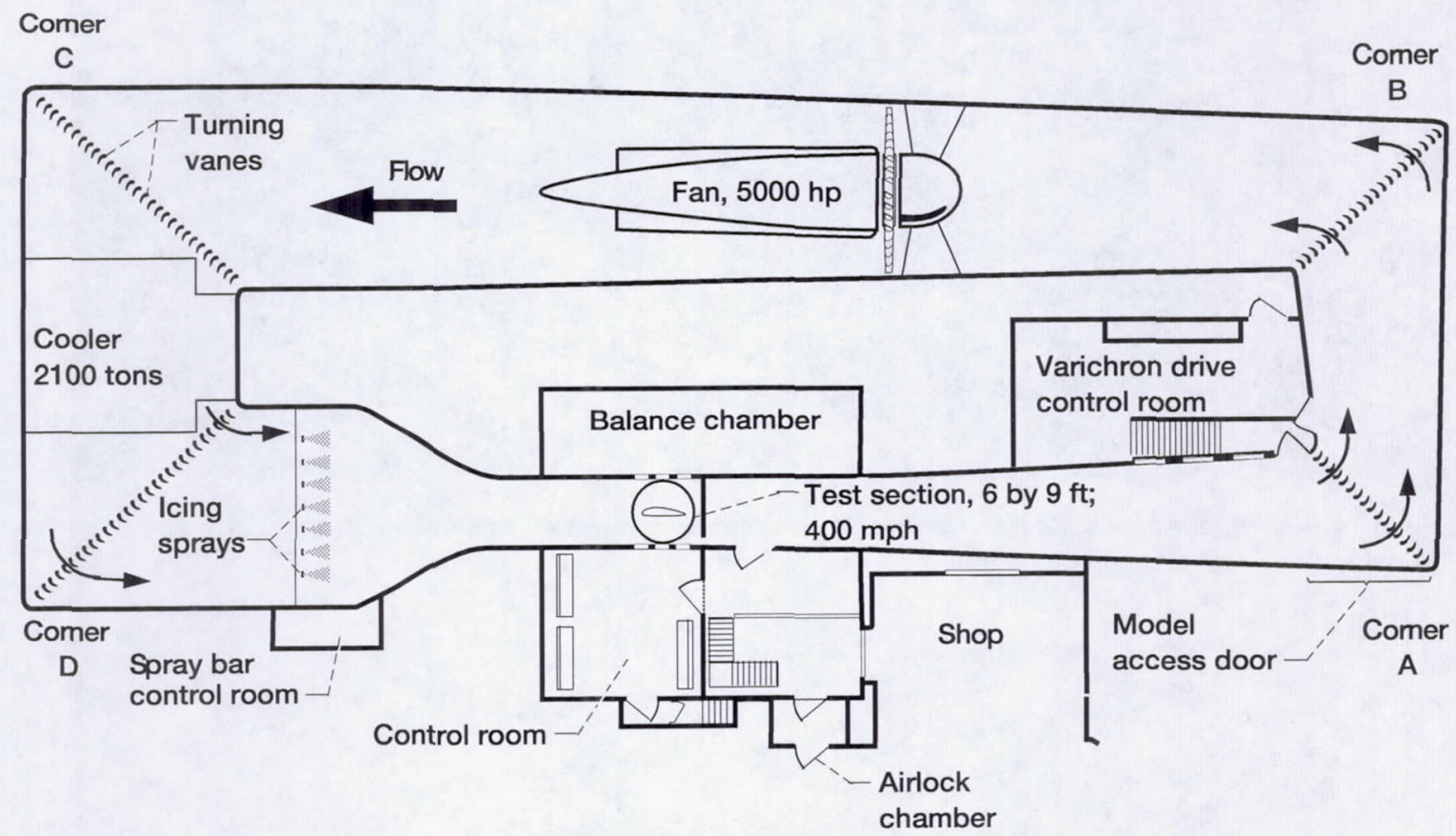

Figure 3.-Plan view of Icing Research Tunnel, shop, and control room. 


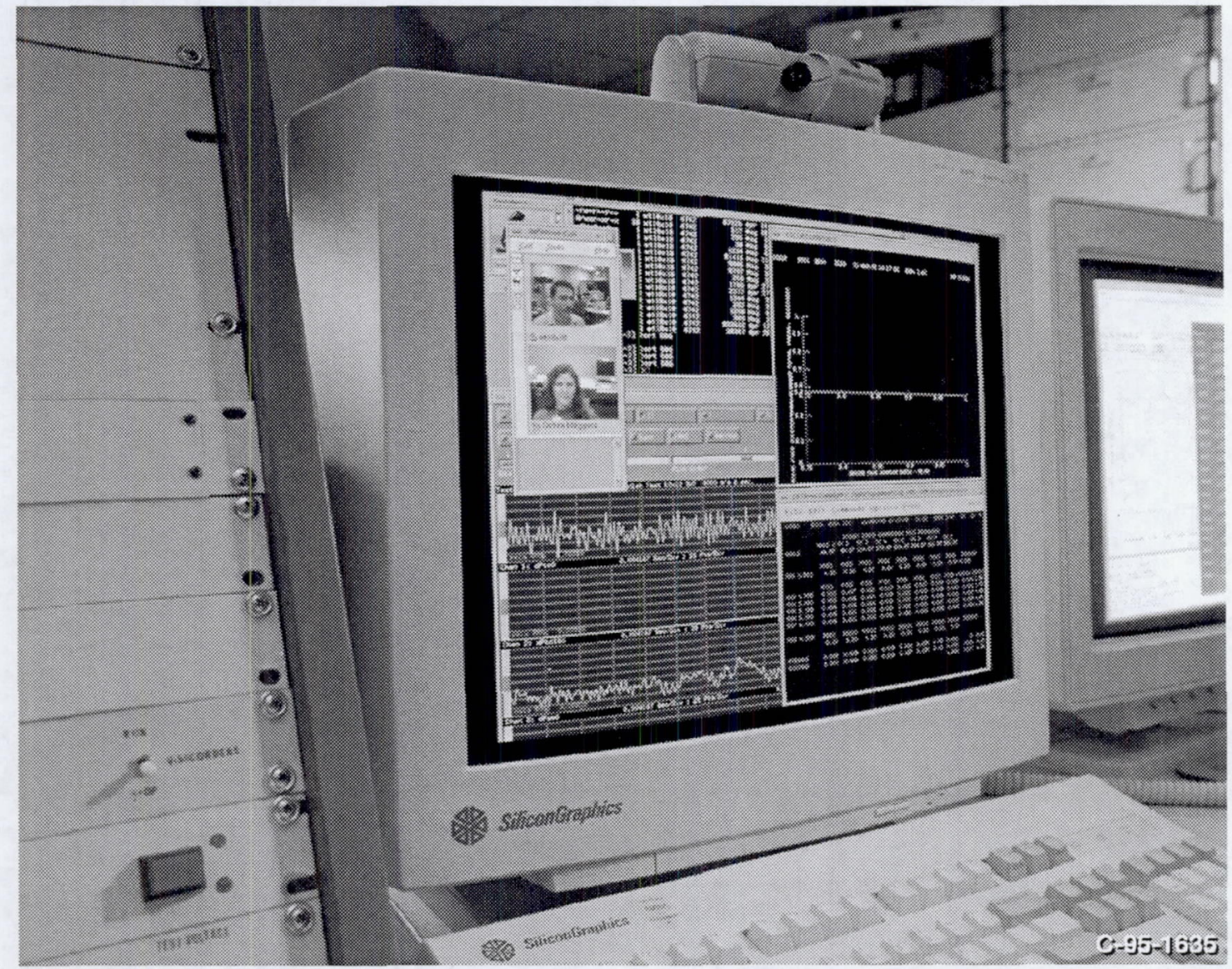

Figure 4.- Remote Access control room computer display showing graphical and tabular steady-state data, dynamic data, and video conferencing options.

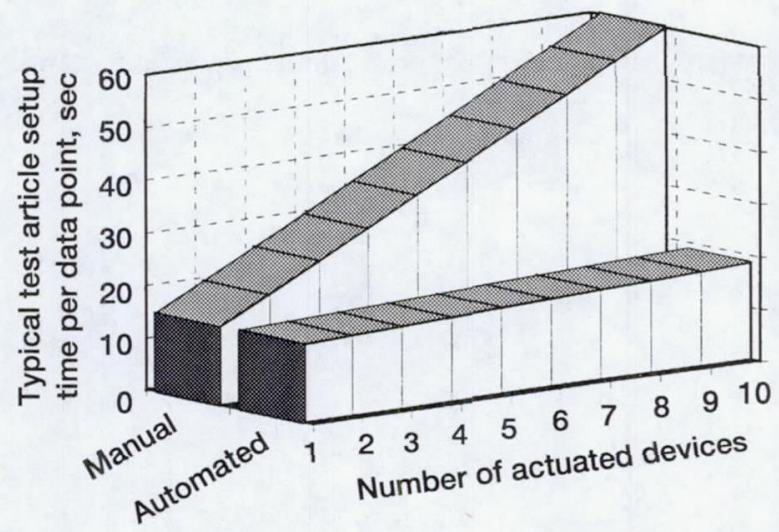

Figure 5.-Comparison of time required to set test condition for manually and automated test articles as function of number of actuators. 


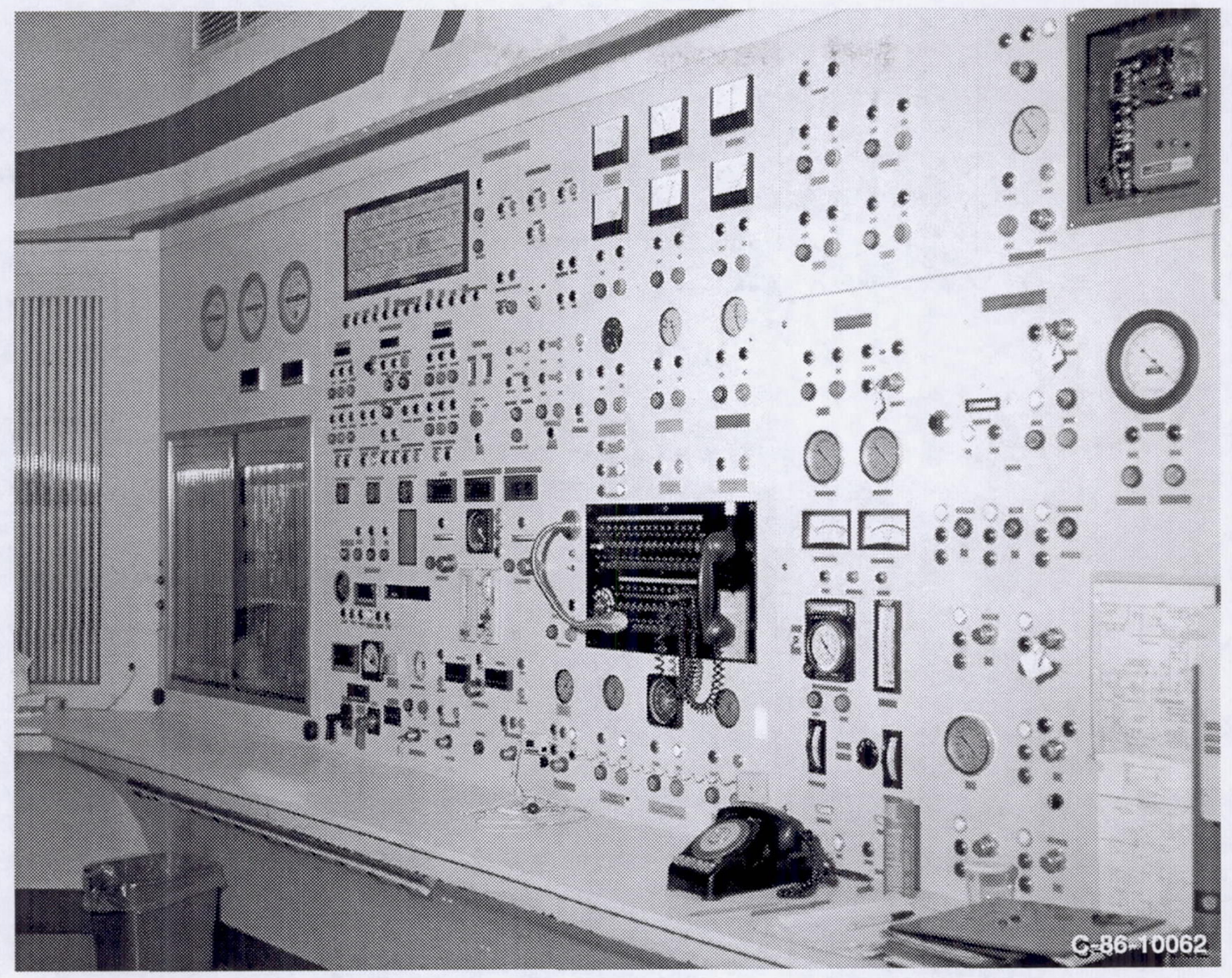

Figure 6.-Discrete control panel (1960-vintage) used in 8- by 6-Foot Supersonic Wind Tunnel.

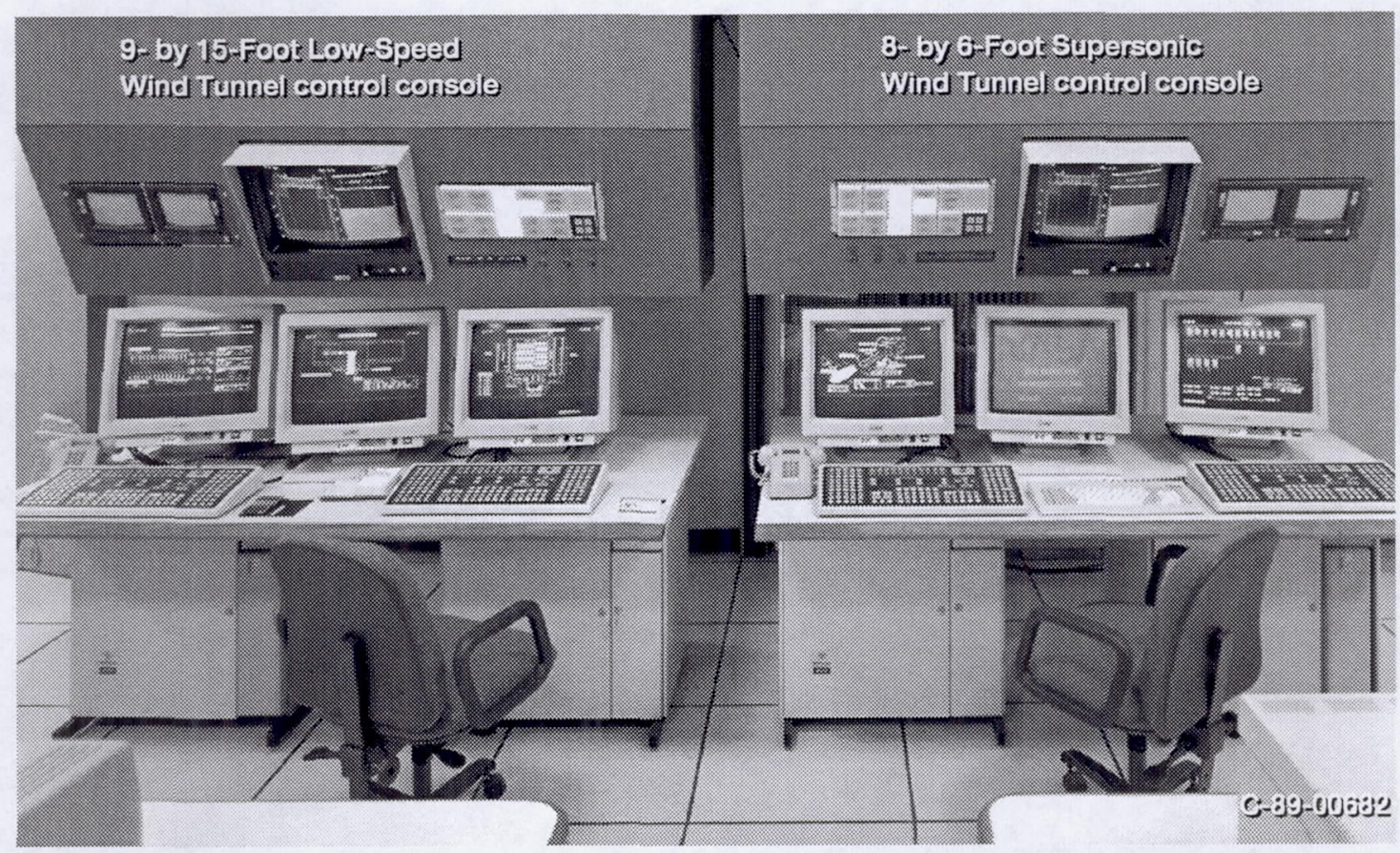

Figure 7.-New distributed control console used in 8- by 6-Foot Supersonic Wind Tunnel. 


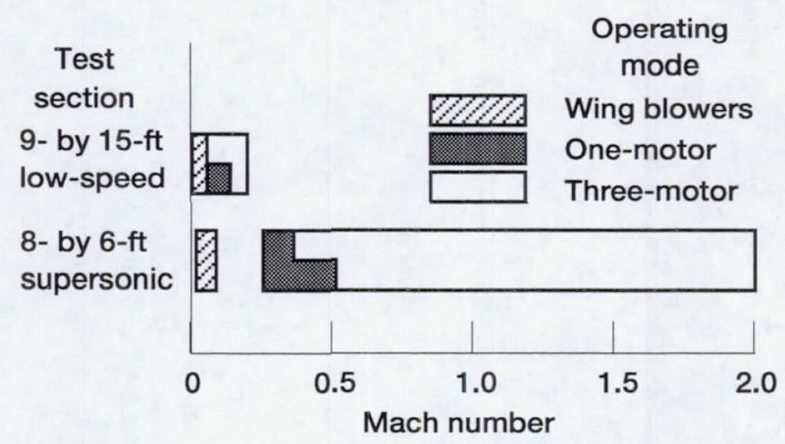

Figure 8.-Current operating ranges of 8 - by $6-\mathrm{ft}$ supersonic and 9 - by 15 -ft low-speed test sections for each operating mode.

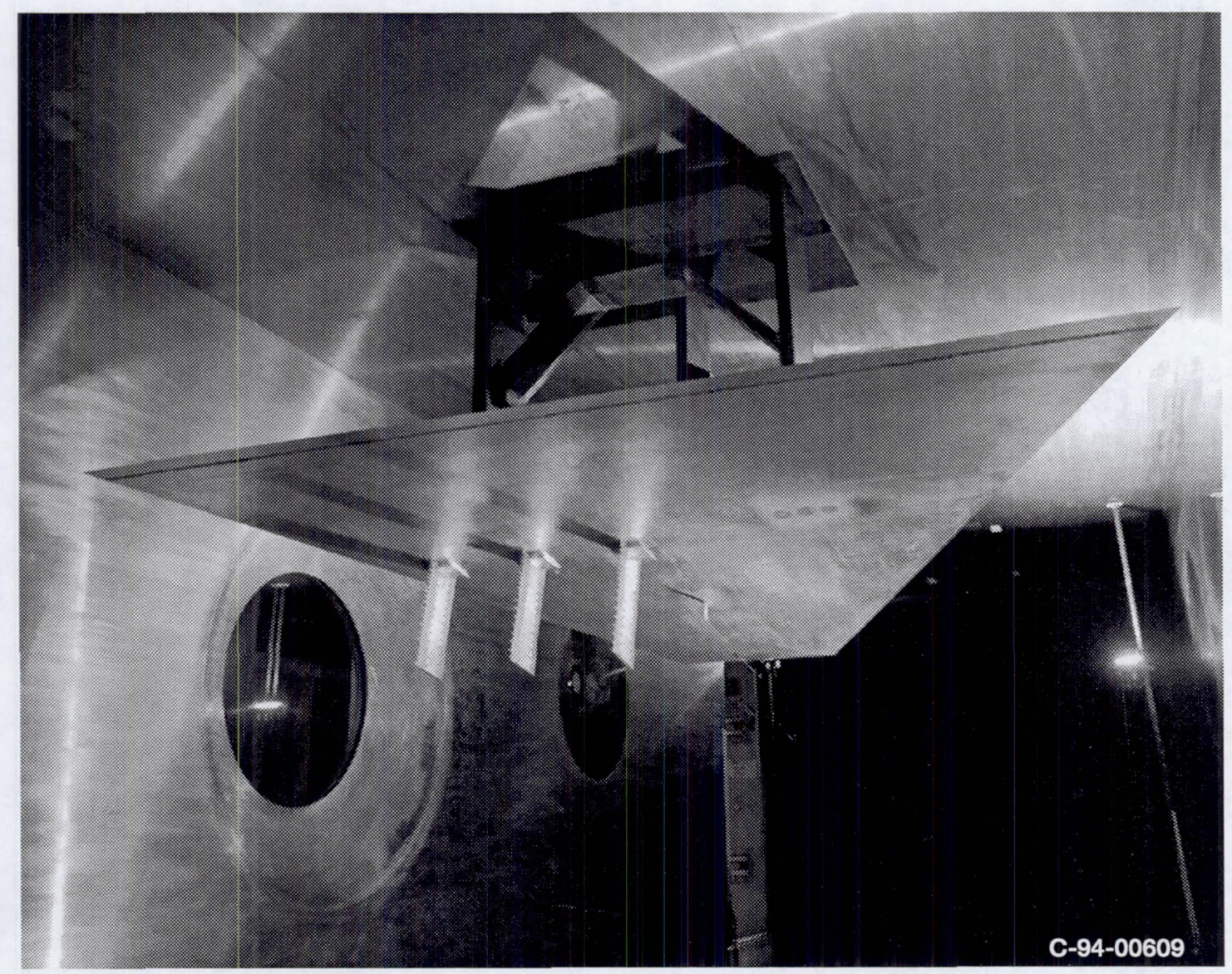

Figure 9.-Typical gust plate installation in 10- by 10 -Foot Supersonic Wind Tunnel. 


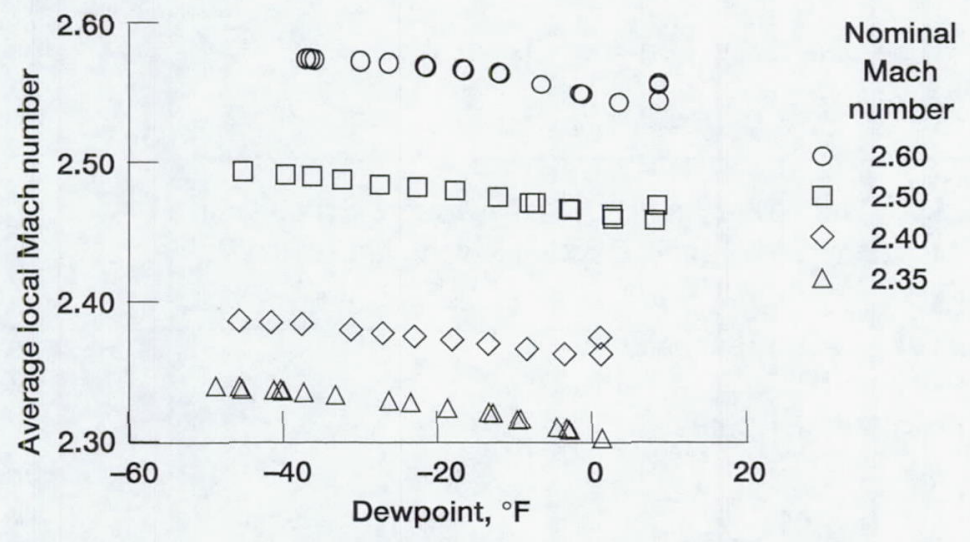

Figure 10.-Variation of average test section Mach number with dewpoint in 10 - by 10 -Foot Supersonic Wind Tunnel for selected Mach numbers.

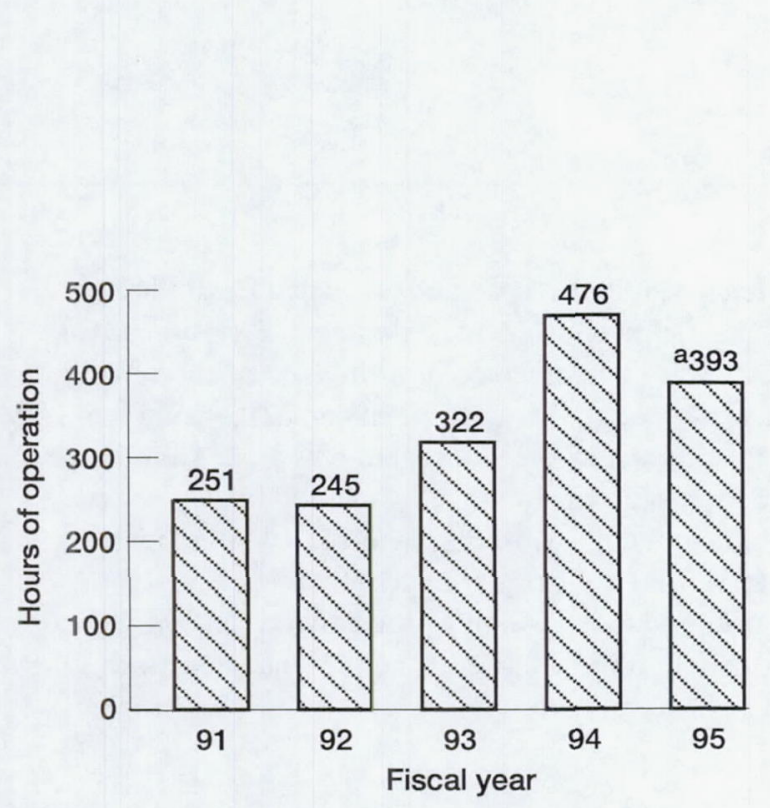

Figure 11.-Annual hours of operation (run hours) for 10 - by $10-$ Foot Supersonic Wind Tunnel. aFacility on standby status for 4 months of FY95.

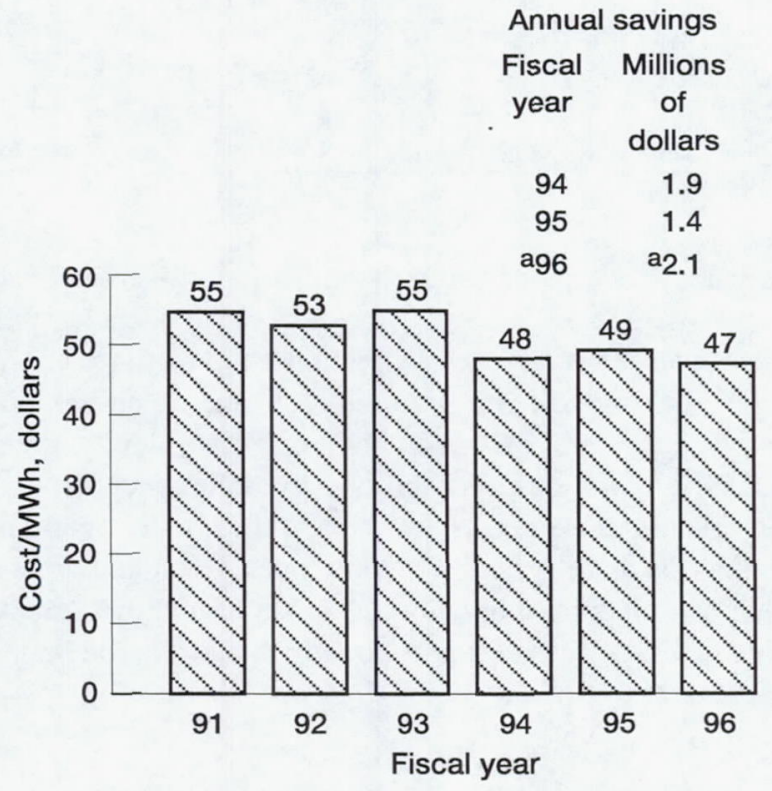

Figure 12.-Laboratory-wide cost of electric power by fiscal year and annual saving since implementation of Project Oriented Third Shift Operations. aBased on projected usage for FY96. 
Public reporting burden for this collection of information is estimated to average 1 hour per response, including the time for reviewing instructions, searching existing data sources, gathering and maintaining the data needed, and completing and reviewing the collection of information. Send comments regarding this burden estimate or any other aspect of this collection of information, including suggestions for reducing this burden, to Washington Headquarters Services, Directorate for Information Operations and Reports, 1215 Jefferson Davis Highway, Suite 1204, Arlington, VA 22202-4302, and to the Office of Management and Budget, Paperwork Reduction Project (0704-0188), Washington, DC 20503.

\begin{tabular}{|l|l|l} 
1. AGENCY USE ONLY (Leave blank) & $\begin{array}{c}\text { 2. REPORT DATE } \\
\text { June } 1996\end{array}$ & $\begin{array}{r}\text { 3. REPORT TYPE AND DATES COVERED } \\
\text { Technical Memorandum }\end{array}$
\end{tabular}

4. TITLE AND SUBTITLE

An Overview of Aeropropulsion Wind Tunnel Productivity Improvements at the NASA Lewis Research Center

\section{AUTHOR(S)}

Allen Arrington, Edward Becks, Philip Blumenthal, John DeArmon, Gary Klann, Timothy Bencic, Timothy McCartney, Joe Panek, Osvaldo Rivera, James Roeder, and David Stark

\section{PERFORMING ORGANIZATION NAME(S) AND ADDRESS(ES)}

National Aeronautics and Space Administration

Lewis Research Center

Cleveland, Ohio 44135-3191

\section{SPONSORING/MONITORING AGENCY NAME(S) AND ADDRESS(ES)}

National Aeronautics and Space Administration

Washington, DC 20546-0001

\section{FUNDING NUMBERS}

$$
\text { WU-505-62-82 }
$$

8. PERFORMING ORGANIZATION REPORT NUMBER

$$
\text { E-10221 }
$$

\section{SUPPLEMENTARY NOTES}

Prepared for the 19th Advanced Measurement and Ground Testing Technology Conference sponsored by the American Institute of Aeronautics and Astronautics, New Orleans, Louisiana, June 17-20, 1996. Allen Arrington, Edward Becks, Philip Blumenthal, and John DeArmon, NYMA, Inc., 2001 Aerospace Parkway, Brook Park, Ohio 44142 (work funded by NASA Contract NAS3-27186); Gary Klann, Timothy Bencic, Timothy McCartney, Joe Panek, Osvaldo Rivera, James Roeder, and David Stark, NASA Lewis Research Center. Responsible person, Gary Klann, organization code 2830, (216) 433-5715.

12a. DISTRIBUTION/AVAILABILITY STATEMENT

12b. DISTRIBUTION CODE

Unclassified -Unlimited

Subject Category 09

This publication is available from the NASA Center for AeroSpace Information, (301) 621-0390.

13. ABSTRACT (Maximum 200 words)

Enhancing wind tunnel test productivity in terms of increased efficiency, reduced cost, and expanded flexibility is a high-priority goal of the NASA Lewis Research Center's Aeropropulsion Facilities and Experiments Division. Over the past several years, several significant productivity improvements were implemented: test times were shortened by using facility and test article automation; additional flexibility was provided to the research customer by using the remote-access control room and by expanding facility operating envelopes; facility throughput was greatly increased and electric power cost for facility operation reduced by using the three-shift operation. One method being used to reduce electric power costs and expand the facility operating envelop in the 8- by 6-Foot Supersonic Wind Tunnel is operating the drive system with only one of the three drive motors. Metrics are being used to document several categories of facility utilization, which in turn allows tracking of test productivity. This paper provides an overview of the productivity improvements already in place in the large wind tunnels at NASA Lewis and presents plans for future

\begin{tabular}{|c|c|c|}
\hline $\begin{array}{l}\text { 14. SUBJECT TERMS } \\
\text { Wind tunnel; Productivity }\end{array}$ & & \\
\hline $\begin{array}{l}\text { 17. SECURITY CLASSIFICATION } \\
\text { OF REPORT } \\
\text { Unclassified }\end{array}$ & $\begin{array}{l}\text { 18. SECURITY CLASSIFICATION } \\
\text { OF THIS PAGE } \\
\text { Unclassified }\end{array}$ & $\begin{array}{l}\text { 19. SECURITY CLASSIFICATION } \\
\text { OF ABSTRACT } \\
\text { Unclassified }\end{array}$ \\
\hline
\end{tabular}
improvements. 